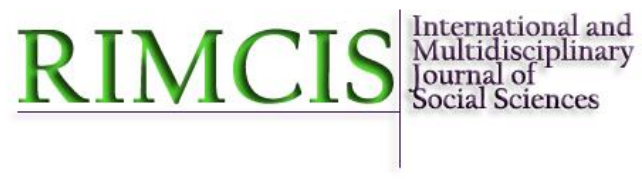

Hipatia Press

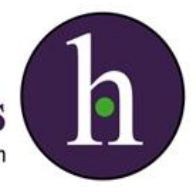

Instructions for authors, subscriptions and further details:

http://rimcis.hipatiapress.com

\section{Child Migration \& Human Rights in a Global Age}

Guiomar Merodio Alonso ${ }^{1}$

1) Universidad de Barcelona. España

Date of publication: November $30^{\text {th }}, 2015$

Edition period: November 2015 - March 2016

To cite this article: Merodio, G. (2015). Child Migration \& Human Rights in a Global Age [Review of the book]. International and Multidisciplinary Journal of Social Sciences, 4(3), 312-314. doi: 10.17583/rimcis.2015.1815

To link this article: http://doi.org/10.17583/rimcis.2015.1815

\section{PLEASE SCROLL DOWN FOR ARTICLE}

The terms and conditions of use are related to the Open Journal System and to Creative Commons Attribution License (CC-BY). 


\section{Review}

Bhabha, J. (2014). Child Migration \& Human Rights in a Global Age. New Jersey: Princeton University Press. ISBN 978-0-691-14360-6

La obra Child Migration \& Human Rights in a Global Age de Jacqueline Bhabha, directora del FXB Center for Health \& Human Rights de la Universidad de Harvard llega en un momento justo y oportuno. La imagen de Aylan, un niño de tres años, refugiado kurdo que emigraba junto con su familia en busca de asilo humanitario y que apareció ahogado en una playa de Turquía en septiembre de 2015 , interpela, a la comunidad científica y a la ciudadanía en general, a reaccionar sobre las situaciones en las que se infringen los derechos humanos de los niños y las niñas migrantes.

En este sentido, Bhabha aborda la interrelación entre los derechos humanos y la migración infantil de forma magistral, rigurosa y desde una perspectiva interdisciplinar. Estudia los efectos de los marcos legales internacionales y las políticas públicas de determinados países en la vulneración o protección de los derechos humanos. Igualmente, examina las dificultades políticas, económicas, sociales, culturales y educativas que afrontan los niños y las niñas migrantes en el mundo actual. La obra se sustenta en un exhaustivo análisis jurídico, sociológico y político de casos reales y representativos, en los que la perspectiva de género se integra permanentemente. El análisis se complementa con aportaciones de la antropología que permiten incluir la diversidad de ciertos grupos sociales, 
así como desde la psicología, aproximándose incluso al impacto que estas trayectorias migratorias tienen en el desarrollo evolutivo y en el bienestar psicológico y emocional durante la infancia y la adolescencia.

La obra se estructura en tres apartados principales en los que las voces de los niños, niñas y jóvenes migrantes, junto con sus experiencias y trayectorias vitales, emergen como protagonistas. Esta aproximación es una de las contribuciones principales de Jacqueline Bhabha, al considerar a los y las menores migrantes como actores principales, agentes activos, ciudadanos y ciudadanas con derechos civiles, rescatándoles así del plano secundario al que tradicionalmente se les ha relegado.

El primer apartado aborda la migración por motivos familiares. A lo largo de tres capítulos trata la reunificación familiar, los niños y las niñas que cruzan irregularmente las fronteras enfrentando innumerables peligros con el propósito de encontrarse con sus familias, la deportación y separación de los miembros de la familia, las familias de refugiados y los claroscuros de la adopción internacional. El segundo capítulo se centra en el drama creciente de la trata infantil, incluyendo la captación, el transporte y la explotación sexual y/o laboral de niños y niñas en el mundo actual; sin olvidar la tragedia del reclutamiento de niños y niñas soldado, como principales víctimas de los conflictos armados. Asimismo, Bhabha explora algunas limitaciones de los gobiernos para erradicar estas problemáticas, y cómo la acción de la sociedad civil está favoreciendo una evolución en las políticas públicas para hacer más efectiva la protección de los derechos humanos, previniendo la trata y el tráfico de menores. El último apartado profundiza en los desplazamientos y la migración de menores como estrategia de supervivencia, incluyendo el caso de los niños y niñas refugiados y de aquellos que buscan un futuro mejor, seguro, en el que sus derechos sean garantizados.

A lo largo de la obra, Jacqueline Bhabha, referente internacional en el ámbito de los derechos humanos y la migración, introduce el concepto de ambivalencia como otra de sus contribuciones principales y novedosas. Según la autora, la persistencia de las desigualdades y vulneraciones que sufren los niños y niñas migrantes en el mundo actual ya no puede explicarse solamente por las teorías de la invisibilidad, sino por la ambivalencia en torno a la que se articulan las políticas públicas y las decisiones legales, 
314 Merodio - Child Migration \& Human Rights [Book Review]

incluyendo el posicionamiento a menudo contradictorio de la ciudadanía ante estas problemáticas. La lectura de Child Migration \& Human Rights in a Global Age contribuye a superar cualquier dilema y doble moral, invitándonos mediante argumentos científicos a posicionarnos y a actuar en favor de los derechos humanos y la protección de la población más vulnerable.

Guiomar Merodio Alonso, Universidad de Barcelona guiomar.merodio@ub.edu 